JOURNAL DE PHYSIQUE IV

Colloque CA, supplément au Journal de Physique III, Vol. 1, novembre 1991

\title{
CYCLING EFFECTS, FATIGUE AND DEGRADATION OF SHAPE MEMORY ALLOYS
}

\author{
J. Van HUMBEECK \\ Dep. MTM-K.U. Leuven, De Croylaan 2, B-3001 Heverlee, Belgium
}

\begin{abstract}
The stability and lifetime of a shape memory device is characterised by the changes of its transformation temperatures, its cold shape, its hot shape, its global two way shape memory effect, its recovery stress. This global behaviour is influenced by a complex combination of internal and external parameters. Internal parameters are : the alloy system, the alloy composition, the type of transformation and the lattice structure including defects. External parameters are : the thermomechanical treatments, the way of training, the applied stress, the imposed shape memory strain, the amplitude of temperature cycling, the absolute temperature of the environment.

The possible physical mechanisms which are at the origin of the limited lifetime of any shape memory element and which are, to a greater or lesser extent, controlled by the above mentioned internal and external parameters, are: the stabilisation of specific martensite variants, the creation of lattice defects during transformation-cycling (transformation plasticity or defects that could trigger unwanted variants), changes in the order of the lattice, changes in defect density and/or defect configuration as a result of ageing.

This paper will present an overview of reported and new observations related to those aspects of shape memory alloys.
\end{abstract}

\section{INTRODUCTION}

The specific functional properties of shape memory alloys, necessitate an extension of the usual definition of fatigue.

Three different types of fatigue have to be considered in the case of shape memory alloys.

1. Failure by fracture due to stress or strain cycling at constant temperature. Three different situations are possible:

- the material is martensitic during cycling;

- the material remains beta during cycling:

- the martensite is stress induced during cycling above the As temperature.

This type of fatigue has so far received the most attention in the literature / 1-20/.

2. Changes in physical, mechanical and functional properties such as the transformation temperatures, the transformation hysteresis, two way memory effect, ... due to pure thermal cycling through the transformation /21-28/.

3. The degradation of the shape memory effect due to stress, strain or temperature cycling in or through the transformation region /30-37/.

The three main parameters to be considered in the study of the global lifetime of a shape memory alloy are thus temperature, stress and the macroscopic shape strain during deformation. It might be 
important for the latter to distinguish between the transformation induced plasticity, this is the shape strain under load during the forward transformation and the spontaneous shape strain due to the one or two way memory effect.

The origin of the global lifetime or fatigue behaviour of shape memory alloys is due to accumulation of defects and structural changes like the change in order of the beta phase or martensite or the formation of other types of martensite. All types of changes will have an influence on the transformation temperatures, the transformation hysteresis, the reproducibility of the one and two way memory effect, and the amount of cycles before fracture.

Generally, the main concern in the lifetime of a shape memory alloy is the stability of the required shapes at different temperatures or the stability of recovery stress or work output.

Therefore information on the temperature and stress profile including the amount of cycles during the required lifetime is a prerequisite to make the proper choices in alloy composition. thermomechanical treatment and design.

This paper will present some important results related to classic fatigue, thermal cycling and degradation of the shape memory effect.

\section{FAILURE BY FRACTURE}

Classic fatigue implies accumulation of defects, formation of cracks and crack propagation until final rupture. This type of behaviour is represented by a schematic Wöhler curve in fig. 1, while fig. $2 / 20 /$ and $3 / 18 /$ show this type of plots for respectively Ni-Ti and Cu-Zn-Al.

The big scatter in the Wöhler curves provides in fact poor reliable data and contains mainly qualitative information. For example fine grained alloys have a higher fatigue resistance than coarse grained alloys (fig. 3). Other reasons for low fatigue life might be the presence of inclusions, segregation of impurities to the grain boundaries or the quality of the surface.

Other factors that makes a comparison between the present results difficult are the differences in experimental conditions such as the $R$-value (the ratio of the minimum and maximum stress of the applied stress cycle) or the use of stress or strain controlled fatigue tests.

So far the presented wöhler curves can certainly not be used as standard information for the prediction of this type of fatigue farlure.

Other information becomes available using $(\mathrm{da} / \mathrm{dN}, \log \Delta \mathrm{K}$ ) plots (fig. 4). da/dN is the change in crack length a versus the amount of cycles $N$. $\Delta K$ is the stress intensity factor. $\Delta K=K_{\max }-K_{\min }$ in which $K_{\max }=\mathrm{C} \sigma_{\max } V_{\pi \mathrm{a}}$ resp. $K_{\min }=\mathrm{C}, \sigma_{\min } V_{\pi \mathrm{a}}$. $\sigma_{\max }$ and $\sigma_{\min }$ are the maximum and minimum stress during cycling. Their ratio $\mathrm{R}=\sigma_{\min } / \sigma_{\max }$ is an important parameter in fatigue.

Although this type of presentation is becoming an increasing standard for fatigue design only a few results have been reported in the case of shape memory alloys. Fig. 5 shows such a plot for $\mathrm{Cu}$ based alloys $/ 3 /$, fig. 6 for Ni-Ti $/ 19 /$.

An important value derived from this type of curves is the lower fatigue threshold value $\Delta \mathrm{K}_{\mathrm{Tr}}$ at $\mathrm{da} / \mathrm{dN}=0$, determined by extrapolation. If one compares fig. 4 and fig. $5, \Delta \mathrm{K}_{\mathrm{Tr}}$ is much higher for $\mathrm{Cu}$-based alloys than for $\mathrm{Ni}-\mathrm{Tl}$. This would mean that $\mathrm{NI}-\mathrm{TI}$ has a worse fatigue resistance than $\mathrm{Cu}$ based alloys, which is opposite from previous experiences.

In fact both curves, fig. 5 and 6 , should not be compared as long as the experimental conditions are not the same.

Other reasons might be different crack initiation and crack growth mechanisms $/ 14,20 /$.

A very important observation however is that faster growth rates and lower fatigue threshold values are observed in the transformation microstructure compared with the stable austenite and stable martensite microstructure as shown in fig. $7 / 19 /$.

In fact this is not what one would expect if the strain is generated by the stress induced transformation. However, systematic research on $\mathrm{Cu}-\mathrm{Zn}-\mathrm{Al}$ alloys has revealed that during pseudoelastic loading dislocation defect arrays are created in the interior of the crystal. Those arrays act as local obstacles for the martensitic transformation and lead to the formation of extrusions and holes at the surface, which, with increasing number of cycles, join to form continuous cracks of about $1 \mu \mathrm{m}$ width $/ 1 /$. The dislocation arrays initially change drastically the hardening slope of the stress induced transformation as shown in fig. $8 / 1,6 /$.

In Cu-Al-Ni single crystals one observed that the cracks initially grew parallel to the stress induced martensite plates. Other authors concluded that crack nuclei occur at interphase boundaries $/ 9 /$ or martensite-martensite interfaces /12/.

In polycrystals multiple nucleation cracks occur at grain boundaries which is similar to what happens in regular metals at high plastic strain $/ 14 /$. 
A common finding in the research of single crystals is that the fatigue life is (almost) independent on percent strain, crystal orientation, or even stress $/ 9 /$.

In any case the surface preparation of the samples plays a decisive role in values for $\mathrm{N}_{\mathrm{f}}$, this is the amount of cycles at fracture.

\section{THERMAL CYCLING}

Thermal cycling through the martensitic transformation induces defects. Extensive literature surveys, especially for $\mathrm{Cu}$ based alloys, can be found in the reference list $/ 28,38,39 /$.

Concerning the changes in the macroscopic parameters of the martensitic transformations, like the transformation temperatures or the transformation hysteresis, the situation is less clear. Some authors report an increase of $M_{3} / 3,40 /$, while others report a decrease even for the same type of alloy $/ 28 /$. Simllar contradictions exist for the transformation temperatures $A_{s}$, As and $M_{f}$ as for the hysteresis, which decreases $/ 3,40 /$ or increases $/ 22,41 /$.

Accepting that the experimental observations are correct one has to conciude that several mechanisms, active during thermal cycling, have opposite effects. On one hand, the introduction of defects will generally stabilize the phase in which the defects are created. On the other hand, defects can act as nucleation sites for the transformation and increase the internal friction forces so that the progress of the transformation becomes more difficult. The denstty and configuration of the defects might also be influenced by the grain size, due to high accommodation stresses at the grain boundaries. Defects can also change the (local) order of the phases, giving rise to (local) changes of the transformation temperatures.

Finally, especially in $\mathrm{Cu}$-based alloys one should take into account that the absolute minimum and maximum temperature of the cycle might control the equilibrium order degree. This can give rise to either the stabilisation of the martensite or that of the beta phase. Especially the mechanism of martensite stabilisation is not yet very well explored.

So far, one can only conclude that the effect of transformation cycling on the transformation characteristics is controlled by the composition, the temperature region, the temperature rate, the grain size, ...

An interesting observation has been made by $R$. Stalmans et al. /42/. At first a Cu-Zn-Al sample was thermally cycled through the transformation. Subsequent training caused only a negligible TWME (Two Way Memory Effect) since the transformation path is already "stabilised" during the thermal cycling due to irreversible processes.

\section{DEGRADATION OF THE SHAPE MEMORY EFFECT}

Generally, degradation is considered as the loss of the two way memory effect relative to a reference value $(100 \%)$.

The two way memory effect is expressed as the difference in shape (i.e. the length of a spring, the strain of a bar, the bending angle of a plate) before and after the martensitic transformation.

It has been experienced that the global degradation behaviour is influenced by a complex combination of internal and external parameters. Internal parameters are : the alloy system (Cubased alloys are more prone to degradation than Ni-Ti alloys), the alloy composition, the type of transformation, (i.e. martensite vs R-phase), the lattice structure, including defects. External parameters are the thermomechanical treatment, the training procedure, the applied stress, the imposed shape memory strain, the amplitude of temperature cycling, the average absolute temperature.

To identify the different mechanisms of degradation, a closer loop to the dimensional changes of both the cold and the hot shape is required. R. Stalmans et al. /44/ analysed this in detail and several parameters are identified. In the course of training and degradation, three different types of strain are important: TWME, or the difference in strain between the hot and the cold shape; TWMS ITwo Way Memory Strain), or the difference between the strain of the martensite after $n$ cycles and the strain before cycling; finally RD, the Remained Deformation of the beta-phase after $\mathbf{n}$ cycles. Fig. 9 shows the evolution of RD, TWMS and TWME for a Cu-Zn-Al alloy. Similar results are presented by P. Rodriguez and G. Guénin /45/.

From fig. 9 it is clear that the initial degradation of the two way memory effect is due to an "apparent" permanent strain in the beta-phase. Indeed, the total permanent strain RD is partially due to real plastic deformation of the lattice, partially due to stabilisation of the martensite. The 
latter part can be restored by heating to a temperature higher than the maximum temperature used during the (training) cycles as shown in fig. 10.

As can be seen in fig. 10 the "postponed" memory effect is restored after one overheating cycle.

The results show clear evidence for local stabilisation. The location and origin of the local stabilisation however is not evident but might be either related to stabilised (parts of) variants, or to local stress fields, for example at the grain boundaries.

In any case, alloys that are more sensitive to stabilisation could show therefore faster degradation than others less sensitive to stabilisation.

In case cycling is continued to hundreds or thousands of cycles also the cold shape starts to decline. In other words, the TWMS decreases. Fig. 11 shows the evolution of the length of a trained SMEspring in hot and cold condition as function of cycling under zero loaū ather training under a constant load during 20 cycles. Beside the degradation of the hot shape, siso the cold shape degrades. Fig. 12 shows the evolution of the dimensions of an identical spring which is now cycled under a constant load. In this case the degradation of the cold shape is decreased while the degradation of the hot shape is increased. The latter part may be explained by faster global stabilisation due to the applied stress $/ 46 /$, the former part however, the degradation of the cold shape, is less evident.

Several mechanisms can contribute to the degradation. C. Friend and A.P. Miodownik /32/ observed locally $\alpha^{\prime}$ martensite, stress induced during cycling. This increasingly disrupts the martensite morphology so that the strain output degrades. A second part might be related to the irreversible dislocation debris generated during thermal cycling as mentioned in the previous paragraph. The defect accumulation may also account for the increasing strain of the hot shape. It may also destroy the initial nuclei that trigger normally the appropriate variants. This might be explained by the increase of the amount of misoriented variants.

A third factor could be related to the loss of the proper nuclel during ageing in the beta phase. Contardo showed that the loss of memory depends also on the time the material has been kept in the beta phase. This process is thermally activated $/ 47 /$. The rate of degradation is thus also partially due to the absolute temperatures used during cycling and thus indirectly due to the heating or cooling rate.

Some observations revealed that the rate of degradation is also dependent on the amount of the initial two way memory effect $/ 48 /$, as can be derived from the data in fig. 13. A high IWME will degrade relatively faster than a small TWME. Other influences are the way of training $/ 37 /$, the addition of alloying elements $/ 27 /$, or thermal treatment $/ 34 /$ as explored in Ni-Ti alloys.

An important remark is given by Y. Suzuki $/ 48 /$. He noticed that the degradation in Ni-Ti alloys is related to the size of the hysteresis, the smaller the hysteresis, the lower the degradation. In this respect, the R-phase transition, which shows a very small hysteresis would be the best choice if the amount of cycles has to approach 108. This is indeed confirmed by Suzuki /48/. When the cooling is stopped after the R-transformation but before the martensite starts to grow, an improved lifetime is registered as shown in fig. $14 / 48 /$.

\section{CONCLUSION}

The reliability of a shape memory device depends on its global lifetime performance. Time, temperature, stress, transformation strain and the amount of transformation cycles are the important controlling external parameters. Important internal parameters that determine the physical and mechanical properties mainly are : the alloy system, the alloy composition, the type of transformation and the lattice structure including defects. Those parameters are controlled by the thermomechanical history of the alloy. Changes of those internal parameters give rise to effects as increased frictional forces, stabilisation of martensite, defect generation or annihilation, precipitation.

Quite a lot of data have already been collected but no systematic research has been performed so far. A systematic research could avoid the apparent contradicting results and more reliable predictions of the long-term behaviour of the material could be assessed. This would also provide the decision making arguments in the choice of alloy composition and design, which will in its turn lead to cheaper and more applications in the field of shape memory alloys. 


\section{REFERENCES}

/1/ M. Sade, R. Rapacioli, M. Ahlers, Acta Met. 33 (1985), 487-427.

/2/ M. Sade, M. Ahlers, Scripta Met. 19 (1985), 425-430.

/3/ M. Thumann, E. Hornbogen, Zeit. für Metallk. 79 (1988), 119-126.

/4/ M. Sade, J. Kumpfert, E. Hornbogen, Zeit. für Metallk. 79 (1988), 678-683.

/5/ M. Sade, E. Hornbogen, Zeit. für Metallk. 79 (1988), 782-783.

16/ A. Ritter, N.Y.C. Yang, D.P. Pope, C. Laird, Met. Trans. A 10A (1979), 667-676.

/7/ K.N. Melton, O. Mercier, Mat. Sc. and Eng. 40 (1979), 81-87.

/8/ L. Delaey, J. Janssen, D. Van de Mosselaer, G. Dullenkopf, A. Deruytteris, Seripta Met. 12 (1978), 373-376.

/9/ H. Sakamoto, Trans. JIM 24 (1983), 665-673.

/10/ H. Sakamoto, Y. Kijima, K. Shimizu, Trans. M 23 (1982), 585-594.

$/ 11 /$ L.C. Brown, Met. Trans. A 13A (1982), 26-31.

/12/ H. Sakamoto, K. Shimizu, K. Otsuka, Trans. JIM 22 (1981), 579-587.

/13/ L.C. Brown, Met. Trans. A 10A (1979), 217-224.

/14/ N.Y.C. Yang, C. Laird, D.P. Pope, Met. Trans. A 8 (1977), 955-962.

/15/ C. Lopez de Castillo, S. Hernaez, B.G. Mellor, Journ. of Mat. Sc. 21 (1986), 4043-4047.

/16/ C. Picornell, E. Cesari, M. Sade, Mat. Sc. Forum 56-58 (1990), 741-746.

/17/ S. Miyazaki, Y. Sugaya, K. Otsuka, MRS-proc., Tokyo 1988, 9, p. 257-262.

/18/ J. Janssen, F. Willems, B. Verelst, J. Maertens, L. Delaey, Proc. ICOMAT-82, Leuven 1982, C4-809-815.

/19/ R.H. Dauskardt, T.W. Duerig, R.U. Ritchie, MRS proc., Tokyo 1989, 9 , p. 243-249.

/20/ S. Miyazaki, Y. Sugaya, K. Otsuka, MRS-proc., Tokyo 1989, 9. p. 251-262.

/21/ T. Tadaki, Y. Nakata, K. Shimizu, Trans. JIM 28 (1987), 883-890.

$122 /$ T. Tadaki, M. Takamori, K. Shimizu, Trans. JIM 28 (1987), 120-128.

/23/ Y. Nakata, T. Tadaki, K. Shimizu, Trans. JIM 26 (1985), 646-652.

/24/ J. Perkins, P. Bobowiec, Met. Trans. A 17A (1986), 195-203.

/25/ K. Tsuji, Y. Takegawa, K. Kojima, Mat. Sc. and Eng. Al36 (1991), Ll-L4.

/26/ J. Perkins, W.E. Muesing, Met. Trans. A 14A (1983), 33-36.

127/ J.L. Proft, K.N. Melton, T.W. Duerig, MRS-proc., Tokyo 1988, 9 , p. 159-164.

128/ T. Tadaki, K. Shimizu, MRS-proc., Tokyo 1988, 9 , p. 291-304.

/29/ J. Van Humbeeck, R. Stalmans, Mat. Sc. Forum 56-58 (1990), 405-416.

130/ S. Edo, Journal of Mat. Sc. Letters 24 (1989), 3991-3993.

/31/ Y. Furuya, H. Shimada, M. Matsumoto, T. Harma, J. Japan Inst. Met. $\underline{52}$ (1988), $139-143$.

/32/ C.M. Friend, A.P. Miodownik, Proc. of Int. Conf. on Mart. Transf. (1986), 902-907, ed. Jap. Inst. of Metals.

/33/ K. Murakami, Y. Murakami, K. Mishima, Y. Ikai, J. Japan Inst. Metals 48 (1984), 115 121.

/34/ J. Beyer, B. Koopman, P.A. Besselink, P.F. Willemse, Mat. Sc. Forum 56-58 (1990), 773778.

/35/ Y. Furuya, H. Shimada, M. Matsumoto, T. Hamma, MRS-proc., Tokyo 1988, 9 , $269-274$.

/36/ Y. Suzuki, MRS-proc., Tokyo 1988, 9, 557-567.

/37/ M. Uehara, T. Suzuki, J. Soc. Mat. Sc. Japan 34 (1985), 779-783.

/38/ D. Rios-Jara, G. Guénin, Acta Met. 35 (1987), 109-119.

/39/ J. Perkins, P. Bobowiec, Met. Trans. A 17A (1986), 195-203.

/40/ J. Perkins, W.E. Muesing, Met. Trans. A 14A (1983), 33-36.

141/ A. Amengual, C. Picornell, R. Rapacioli, C. Sëgut, V. Torra, Thermoch. Acta 145 (1989), 101-114.

/42/ R. Stalmans, J. Van Humbeeck, L. Delaey, this conference.

143/ J. Van Humbeeck, R. Stalmans, M. Chandrasekaran, L. Delaey, in "Engineering aspects of shape memory alloys", ed. T. Duerig et al., Butterworth-Heinemann, p. 96-106.

/44/ R. Stalmans, J. Van Humbeeck, L. Delaey, submitted for publication in Acta Met. (1991).

/45/ P. Rodriguez, G. Guénin, Mat. Sc. Forum 55-58 (1990), 541-546.

/46/ M. Mantel, Ph.D. thesis, INSA-Lyon.

147/ L. Contardo, Ph.D. thesis, NX88 ISAL 0048, INSA-Lyon, 1988.

/48/ Y. Suzuki, MRS-proc., Tokyo 1988, 9, ed. MRS 1989, p. 557-567.

/49/ R.O. Ritchie, Metal Science 11 (1977), 368-381.

/50/ W. Akkermans, Master thesis, Dep. MTM-K.U.Leuven, 1989. 


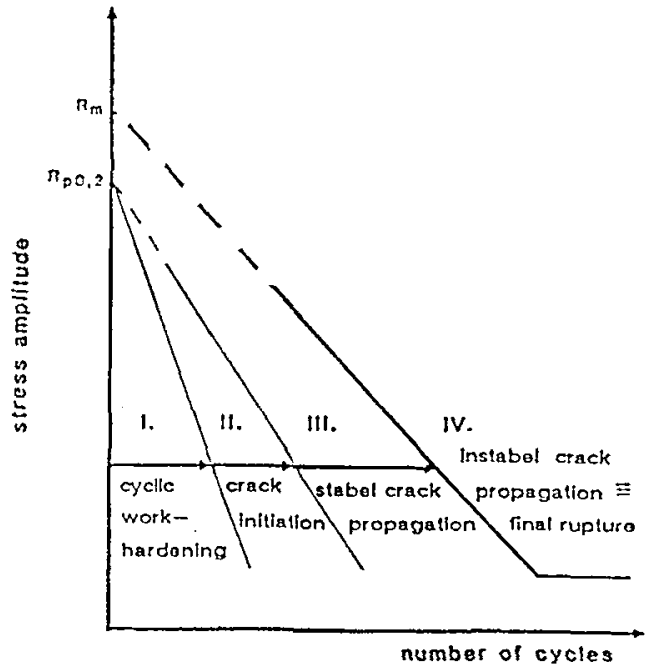

Fig. 1 : schematic $\sigma-N$ diagram showing the four stages of fatigue : (1) accumulation of defects, (2) crack initiation, (3) stable crack growth and (4) final rupture $/ 3 /$.

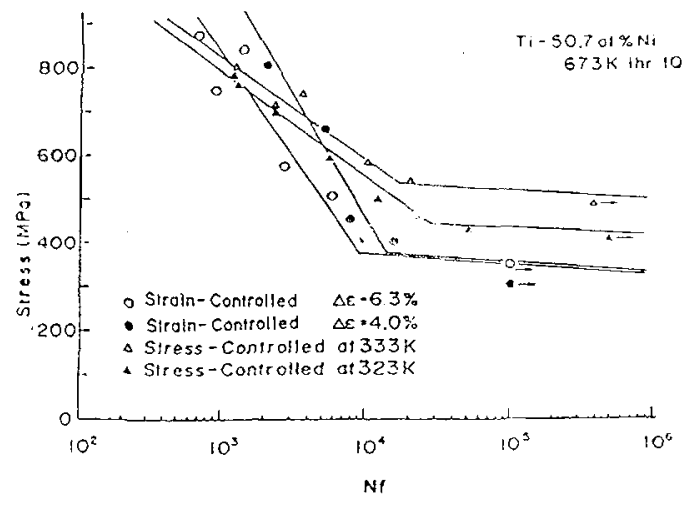

Fig. 2 : fatigue lives measured by stressconstant and straln-constant tests in Ti50.7 at $\% \mathrm{Nl}$ alloy. The stress for the strainconstant test is the one measured at the first cycle $/ 20 /$.

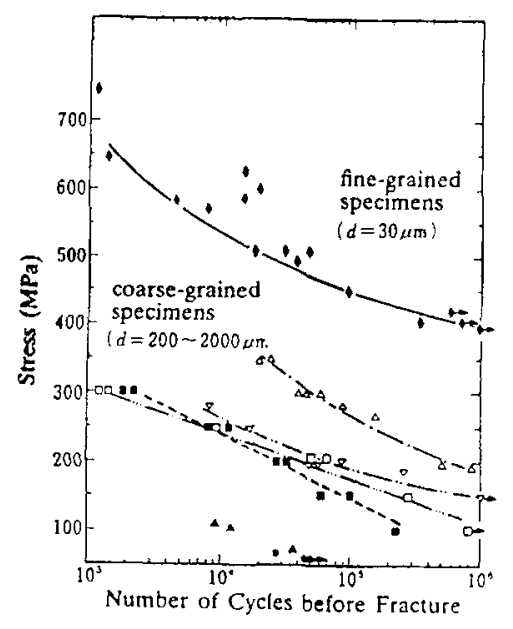

Fig. 3 : fatigue life in fine and coarse-grained specimens $/ 18 /$.

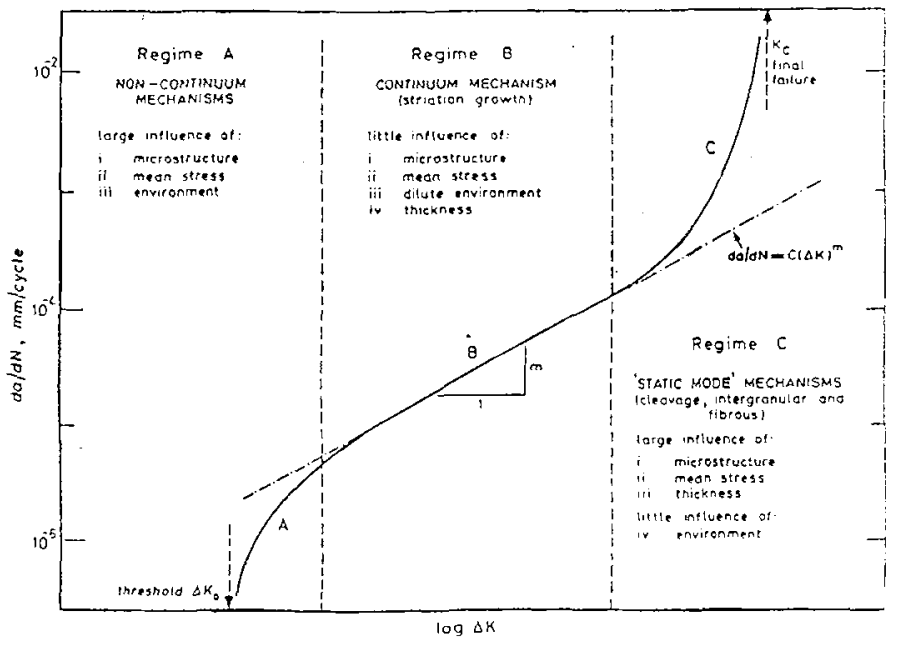

Fig. 4 : primary fracture mechanisms in steels asserlated with sigmoïdal variation of fatigue crack propagation rate $(\mathrm{da} / \mathrm{dN})$ with alternating stress intensity $(\Delta K) / 49 \%$. 


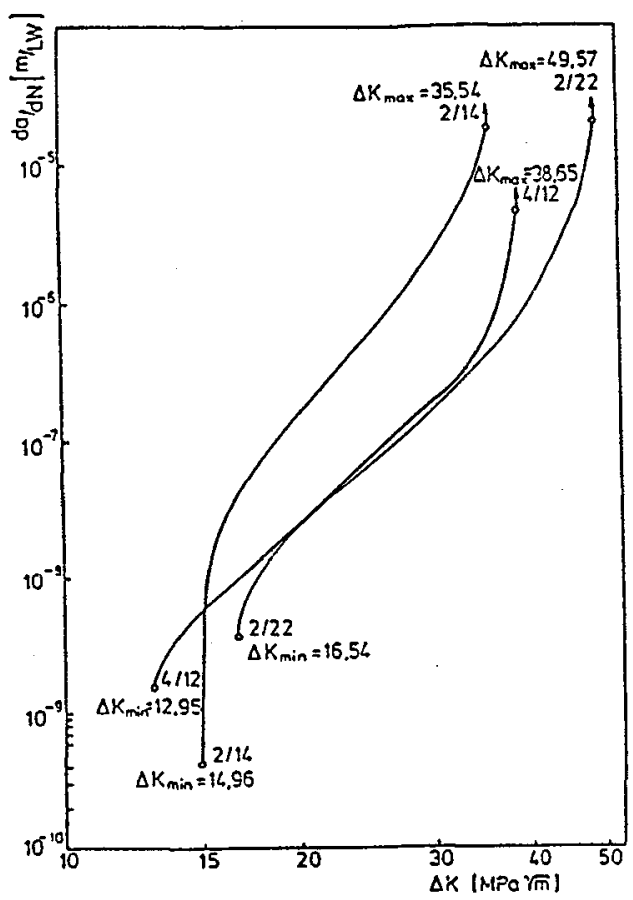

Fig. 5 : fatigue crack propagation in stable $\beta$, martensite $\alpha_{\mathrm{s}}$ and hot rolled $\beta / 3 /$.

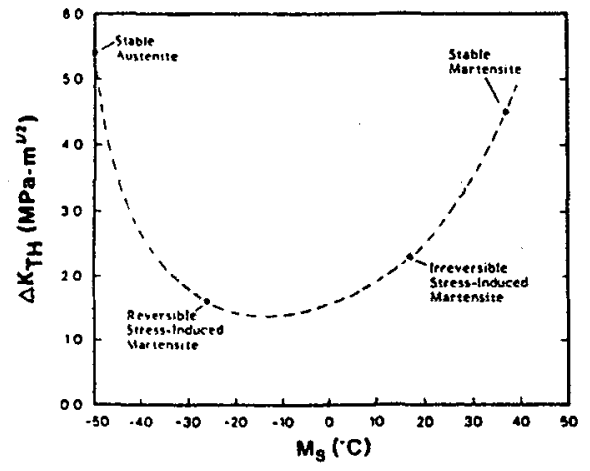

Fig. 7 : variation of the fatigue threshold ( $\left.\triangle \mathrm{K}_{\mathrm{rr}}\right)$ for crack propagation in $\mathrm{Ti}-\mathrm{Ni}$ shape memory alloys as a function of the martensite start temperature M.. Threshold data are taken from the room temperature results plotted in fig. $6 / 19 /$.

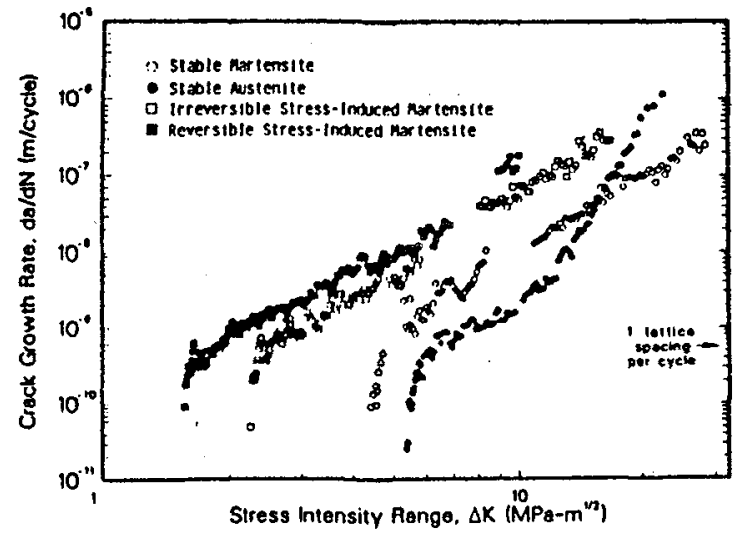

Fig. 6 : variation in fatigue-crack growth rates $(\mathrm{da} / \mathrm{d} N)$ as a function of the stress-intensity range $(\Delta K)$ in near-equiatomic $\mathrm{Ti}-\mathrm{Ni}$ shape memory alloys at room temperature $(R=0.1)$. Note the faster growth rates and lower fatigue threshold $\Delta \mathrm{K}_{\mathrm{rz}}$ values in the transforming microstructures, compared to the stable austenitic and stable martensitic microstructures $/ 19 /$.

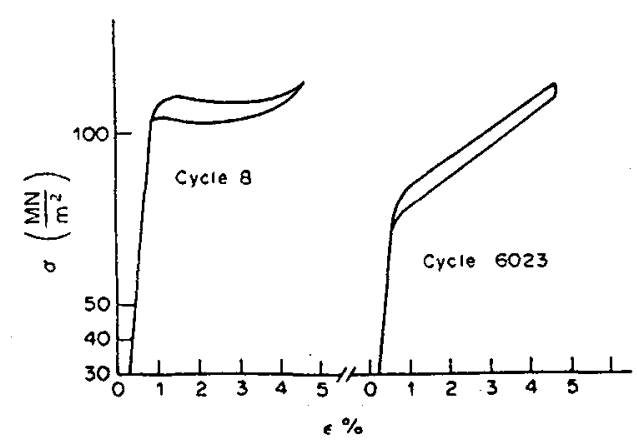

Fig. 8 : stress strain curves of a crystal tested at room temperature during the 8 th and the 6023 th cycle $/ 1 /$. 


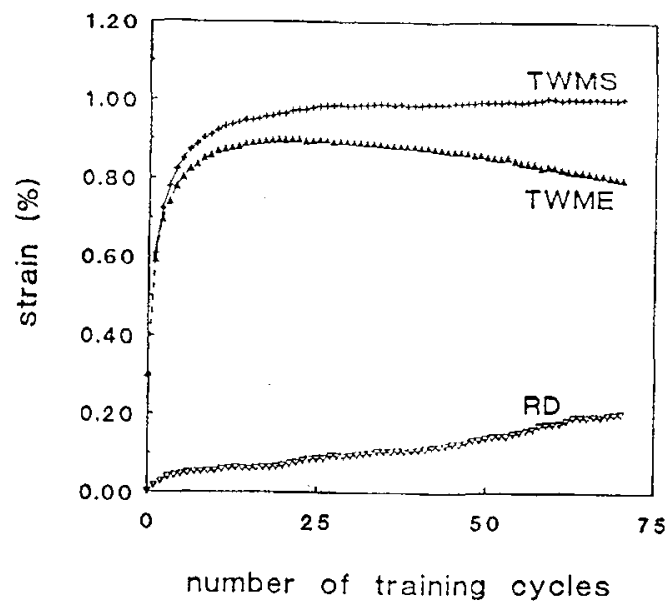

Fig. 9: the evolution of the TWME (Two Way Memory Effect), the TWMS (Two Way Martensitic Strain) and the residual deformation of the austenitic shape $\mathrm{RD}$.

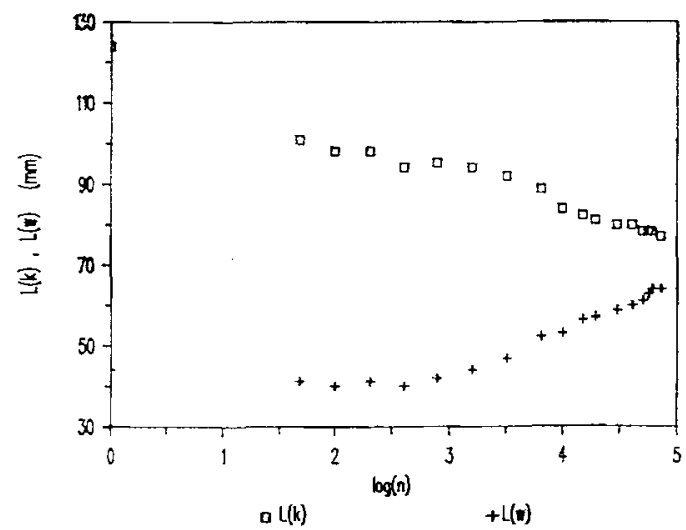

Fig. 11 : the change in length of a spring in austenitic state $(+)$ and martensitic state (D) during load free cycling $/ 50 /$.

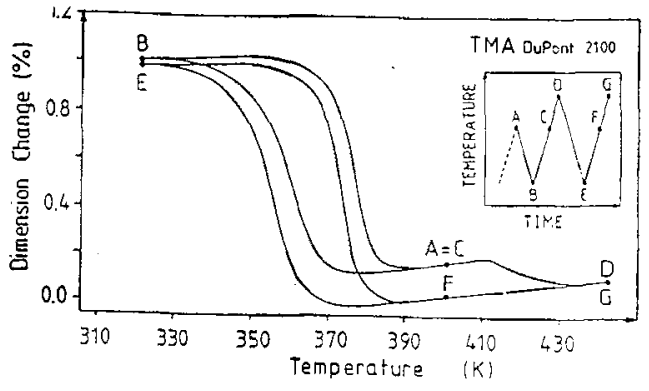

Fig. 10 : the reversion of locally stabilised martensite and the accompanying partial recovery of the austenitic shape by overheating the sample after training.

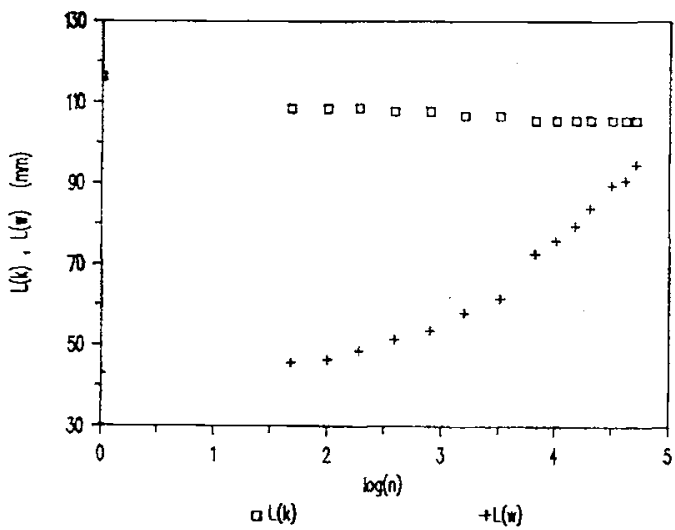

Fig. 12 : the change in length of a spring in austenitic state $(+)$ and martensitic state (G) during cycling under constant load $/ 50 /$. 


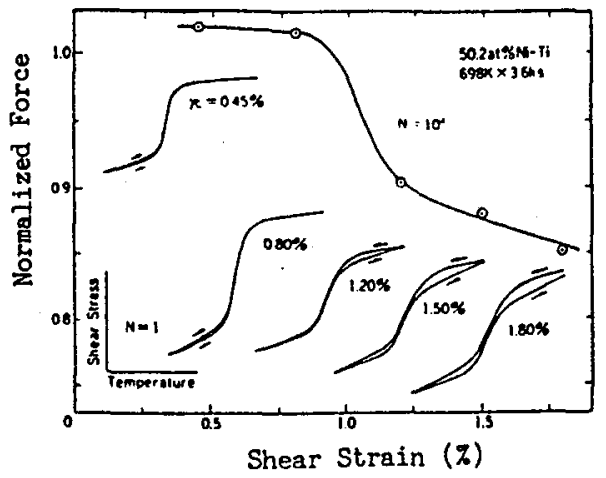

Fig. 13 : change in the recovering force and the corresponding temperature vs recovering force curves $/ 48 /$.

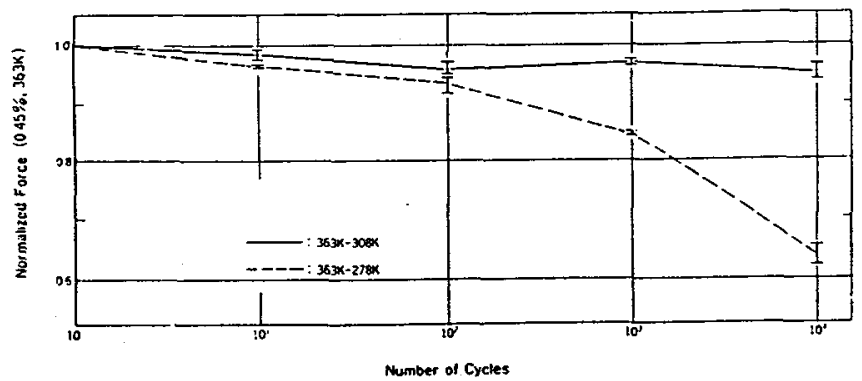

Fig. 14 : change in the recovering forces as a function of the repetition cycles $/ 48 /$. 